\title{
Bioluminescence Microplate Assay of Cyanide with Escherichia coli Harboring a Plasmid Responsible for Cyanide-dependent Light Emission in Alginate Microenvironment
}

\author{
Hajime KaratanI, ${ }^{* 1, * 2, * 3 \dagger}$ Yasuro FuSe, ${ }^{* 1, * 3}$ Hirotaka MizUguCHI, ${ }^{* 3}$ Shogo MonJI, ${ }^{* 1}$ Hiroshi Oyama, $* 4$ \\ Tomonori WAKU, ${ }^{* 1}$ and Masashi IWASAKI $* 3, * 5$
}

*1 Faculty of Molecular Chemistry and Engineering, Kyoto Institute of Technology, 1 Hashigami-cho, Matsugasaki, Sakyo, Kyoto 606-8585, Japan

*2 Kyoto Luminous Science Laboratory, 1 Hashigami-cho, Matsugasaki, Sakyo, Kyoto 606-8585, Japan

*3 Center of Environmental Science, Kyoto Institute of Technology, 1 Hashigami-cho, Matsugasaki, Sakyo, Kyoto 606-8585, Japan

*4 Department of Life Science, Faculty of Science and Engineering, Setsunan University, 17-8 Ikedanaka-machi, Neyagawa, Osaka 572-8508, Japan

*5 Faculty of Materials Science and Engineering, Kyoto Institute of Technology, 1 Hashigami-cho, Matsugasaki, Sakyo, Kyoto 606-8585, Japan

\begin{abstract}
We describe the bioluminescence of a genetically engineered Escherichia coli harboring a recombined plasmid with a catalase gene promoter fused lux gene cluster, responsible for the generation of photons closely associated with respiratory inhibition, with the aim of applying it for cyanide sensing. This E. coli construct was favorably utilized for the microplate assay of cyanide by leveraging the microenvironment of the biocompatible alginate. The brightness of the bioluminescence, induced by cyanide stimulation of the respiration causative of the production of hydrogen peroxide, positively correlates with its concentration. Moreover, visualization of cyanide with a consumer digital camera, ranging in concentration from about $0.01 \mathrm{mg} \mathrm{CN} \cdot \mathrm{L}^{-1}$ in the alginate sol to around $100 \mathrm{mg} \mathrm{CN} \cdot \mathrm{L}^{-1}$ in its gel, was attained.
\end{abstract}

Keywords Bioluminescence, photobacterium, bacterial luciferase, lux gene, microplate assay, Escherichia coli, catalase promoter, cyanide, alginate, microenvironment

(Received March 11, 2019; Accepted May 9, 2019; Advance Publication Released Online by J-STAGE May 17, 2019)

\section{Introduction}

Cyanide is a toxin that occurs in daily life from time to time For example, the hydrolysis of cyanogenic glycoside containing some flowers, some fruits and cassava, which is a staple food in the tropics, gives rise to cyanides..$^{1,2}$ Accidental release of cyanide-containing waste water from plants into the environment has also been reported repeatedly. ${ }^{3}$

It is well known that an intake of cyanide inhibits respiratory electron transport, so that the high energy electrons in the upstream of the electron transport chain leaks out to reduce free $\mathrm{O}_{2}$ to superoxide anions $\left(\mathrm{O}_{2} \cdot\right)$, followed by the enzymatic disproportionation to hydrogen peroxide $\left(\mathrm{H}_{2} \mathrm{O}_{2}\right) .{ }^{4}$ Regardless of species, catalase is soon produced to scavenge excessive $\mathrm{H}_{2} \mathrm{O}_{2}$ for adaptation to oxidative stress. In the scavenging mechanism, $\mathrm{H}_{2} \mathrm{O}_{2}$ oxidizes the stress sensor protein OxyR in the reduced form so as to fit to the regulatory region of a catalase coding

† To whom correspondence should be addressed.

Present address: Kyoto Luminous Science Laboratory, Keihanna Plaza, Laboratory Wing, 1-7 Hikaridai, Seika-cho, Soraku, Kyoto 619-0237, Japan.

E-mail: karatani@kit.ac.jp; karatani@environ.kit.ac.jp gene $(k a t G)$, leading to the activation of its production. ${ }^{5}$

Focusing on the utilization of a catalase regulatory region $\left(k a t G^{\prime}\right)$, it should be noted that by fusing it to a gene of interest, its expression becomes $\mathrm{H}_{2} \mathrm{O}_{2}$-dependent. ${ }^{6}$ A lux gene cluster responsible for the bacterial bioluminescence has also been fused to $k a t G^{\prime}$ for use as oxidative stress sensor. ${ }^{7-9}$ Without limitation to the bacterial lux gene, the gene engineering technique is generally beneficial in the development of a bioluminescence-based sensor. ${ }^{10}$

Regarding the structure of the lux gene, several structures have been identified to date. ${ }^{11,12}$ In particular, $\operatorname{lu} x C D A B E$ has widely been utilized for the reporter gene. ${ }^{7-9,13}$ Bacterial bioluminescence is basically produced in the following luciferase reaction (1);14

$$
\begin{aligned}
\mathrm{FMNH}_{2}+\mathrm{O}_{2}+\mathrm{RCHO} \stackrel{\text { Luciferase }}{\longrightarrow} & \mathrm{FMN}+\mathrm{RCOOH}+\mathrm{H}_{2} \mathrm{O}+ \\
& \text { light }\left(\lambda_{\max } \sim 490 \mathrm{~nm}\right)
\end{aligned}
$$

In this reaction, $\mathrm{FMNH}_{2}$ is reduced riboflavin $5^{\prime}$-monophosphate, $\mathrm{RCHO}$ is a long-chain aliphatic aldehyde and $\mathrm{RCOOH}$ is the corresponding fatty acid. Bacterial luciferase is encoded by $\operatorname{lu} x A$ and $\operatorname{lu} x B$. On the other hand, $\operatorname{lu} x C, \operatorname{lux} D$, and $\operatorname{lu} x E$ code the $\mathrm{RCHO}$ recycling enzymes. A weakness of the lux CDABE is that the resultant light is not so strong. Among the luminous species, luxCDABFEG originating from the Photobacterium 
phosphoreum species appears to cause the most intense bioluminescence. ${ }^{15}$

Recently, we have succinctly described a fusion gene consisting of a partial sequence of $\mathrm{kat}^{\prime}$ (251bp) and Photobacterium's luxCDABFEG (7158bp). ${ }^{16}$ Unfortunately, the ability of $E$. coli transformed with a plasmid carrying this fusion gene as an insert was insufficient to induce bioluminescence efficiently in response to $\mathrm{H}_{2} \mathrm{O}_{2}$ stimulation. Since the sequence of luxCDABFEG, isolated from $P$. phosphoreum strain bmFP, ${ }^{17}$ is partially different from the reported one, ${ }^{11}$ this lux gene is referred to by the strain name bmFPluxCDABFEG, hereinafter.

Based on the preliminary results, the full length of $k a t G^{\prime}$ (501bp), originating from $E$. coli $\mathrm{K} 12$, was utilized to fuse to the bmFPlux gene cluster. In the preparation of the fusion gene, luxG moiety was truncated because it does not seem to participate in the bioluminescence production. Indeed, bmFPluxCDABFE (6437bp) gave a strong bioluminescence. Additionally, the $\mathrm{T} 7$ promoter region of pETBlue-2 plasmid was intentionally retained in the insertion of the fused gene for the efficient evaluation of the basic performance of the fusion gene. E. coli, bearing the fusion-gene cloned plasmid, is called E. coli-kat $G^{\prime}:$ bmFPluxCDABFE.

It was also shown that not only the alginate microenvironment ${ }^{18-20}$ is profitable to enhance the bioluminescence of the luminous $E$. coli construct, but also that the light production suitable for visualization of cyanide can be delayed for several hours or more by immobilizing the cells in the alginate gel. Regarding the microenvironments of the biological macromolecules, agarose gel has also been favorably utilized for the colorimetric detection of cyanide. ${ }^{21}$

\section{Experimental}

Preparation of the fusion gene and characterization of the effect of alginate viscosity are described in detail in Supporting Information.

\section{Chemicals}

Cyanide standard solutions were prepared from potassium cyanide (Wako Pure Chemical industries, Osaka, Japan) in fresh liquid medium. Sodium alginate $(80-120 \mathrm{mPa} \cdot \mathrm{s})$ was from Wako Pure Chemicals. Other chemicals were of analytical chemical grade. Biochemicals used are described in the following paragraph and in Supporting Information.

\section{Plasmid and E. coli cells}

Plasmid used was pETBlue-2 (Novagen, Madison, USA). E. coli HST08 (TaKaRa Bio Inc., Shiga, Japan) was used to amplify the recombined plasmid. The host cell used for the bioluminescence production was E. coli BL21 (DE3) (Nippon Genes, Tokyo, Japan).

\section{Basic bioluminescence properties of E. coli-kat $G^{\prime}:: b m F P l u x-$} CDABFE

Cell growth was initiated by adding $1 \mathrm{~mL}$ of $10 \mathrm{v} / \mathrm{v} \%$ glycerol stock to a $50-\mathrm{mL}$ LB liquid medium $(\mathrm{pH} 7.2)$ containing $50 \mu \mathrm{g} \mathrm{mL}^{-1}$ carbenicillin and then shaken at $37^{\circ} \mathrm{C}$. When the turbidity of the culture $\left(\mathrm{OD}_{600}\right.$, as an indicator of the cell population) reached around 0.4 , it was equally split into four 10 -mL cultures in four 50 -mL tubes and cooled to about $20^{\circ} \mathrm{C}$ on ice. To each split $10-\mathrm{mL}$ culture, either $20 \mu \mathrm{L}$ of $400 \mathrm{mmol} \mathrm{L}^{-1}$ isopropyl $\beta$-D-1-thiogalactopyranoside (IPTG) (Wako) or $20 \mu \mathrm{L}$ of $0.010 \mathrm{~mol} \mathrm{~L}^{-1} \mathrm{H}_{2} \mathrm{O}_{2}$ (Wako) was added. Additionally, $200 \mu \mathrm{L}$ of various concentrations of cyanide, prepared with fresh LB medium, was also added to the culture in a similar manner as above. The bioluminescence spectrum and $\mathrm{OD}_{600}$ of the split culture were recorded at regular time intervals with $1 \mathrm{~mL}$ of the culture, and it was returned to each split culture. The area of the bioluminescence spectra between 400 and $650 \mathrm{~nm}$ was regarded as light intensity. Temperatures suitable for the induction of the bioluminescence were about $20^{\circ} \mathrm{C}$ or somewhat less. So, a series of bioluminescence measurements and photographs were taken at about $20^{\circ} \mathrm{C}$.

\section{Bioluminescence assay of cyanide using luminous E. coli in alginate sol}

First, E. coli-kat $G^{\prime}:$ bmFPluxCDABFE cells were pre-cultured in liquid $\mathrm{LB}$ medium at $37^{\circ} \mathrm{C}$. When the $\mathrm{OD}_{600}$ of the culture reached the range of 1 to 2 , the preculture was cooled to about $20^{\circ} \mathrm{C}$ on ice. The cooled preculture was mixed with $2 \mathrm{w} / \mathrm{v} \%$ alginate containing LB medium, precooled to about $20^{\circ} \mathrm{C}$, to be 1-to- 2 or 1-to-1 in volume ratio, and then $100 \mu \mathrm{L}$ each of the mixture was dispensed in 96 wells of a microplate. Subsequently, $15 \mu \mathrm{L}$ of various concentrations of cyanide standard solution was added to each well. For IPTG, $15 \mu \mathrm{L}$ of $1.6 \mathrm{mmol} \mathrm{L}^{-1}$ of IPTG was added. In the case of the control, $15 \mu \mathrm{L}$ of a fresh LB medium free of cyanide or IPTG was added. After gently shaking the plate, the microplate was photographed in the light tight box as a function of time.

Bioluminescence assay of cyanide using luminous E.coli immobilized alginate gel

Prior to immobilization, E. coli-kat $G^{\prime}:$ bmFPluxCDABFE cells were precultured in liquid medium until $\mathrm{OD}_{600}$ of the culture reached a range of 0.6 to 1 , and the preculture was mixed with $2 \mathrm{w} / \mathrm{v} \%$ alginate containing liquid medium to be 1-to-1 in volume ratio. Subsequently, a fixed volume of the mixture was dropped in a $\mathrm{Ca}^{2+}$ solution prepared either from calcium lactate or from calcium chloride. $\mathrm{Ca}^{2+}$ concentration was usually $1 \mathrm{w} / \mathrm{v} \%$. A spherical gel to fit in a well of a 96-well microplate was prepared from $240 \mu \mathrm{L}$ of the alginate containing culture. The gel was soon shaped spherically in the $\mathrm{Ca}^{2+}$ solution and the resultant gel was further kept in it for $10 \mathrm{~min}$ to complete the gelation. Subsequently, the gel spheres were scooped with a tea strainer and washed with the fresh liquid medium twice to wash out free $\mathrm{Ca}^{2+}$ ions. After gently wiping off the washing medium from the gel surface with paper, luminous E. coli immobilized alginate gels were put in each well and then $25 \mu \mathrm{L}$ of either cyanide standard solution or IPTG solution was added to each well. In the case of gels in the 24well microplate, each well was packed with five gel balls and $750 \mu \mathrm{L}$ of either cyanide standard solution or of IPTG solution was added to each well. For the control, 25 or $750 \mu \mathrm{L}$ of a fresh liquid medium was added. After the addition, photographing of the microplate was carried out in the dark at the fixed times.

\section{Apparatus}

Bioluminescence spectral measurements were recorded with by a Shimazu spectrofluorophotometer RF5300PC (Kyoto, Japan) with the excitation light off. Optical density at $600 \mathrm{~nm}$ of the cell culture was recorded with a JASCO spectrometer Model 630 (Hachioji, Japan). Polymerase chain reaction (PCR) was carried out by a BioRad iCycler (Hercules, CA, USA). Microplate bioluminescence was photographed by a Nikon digital camera D3100 with a Nikkor Lenz AF-5 Micro Nikkor $60 \mathrm{~mm} \mathrm{f} / 2.8 \mathrm{G}$ ED in a home-made light tight box. Exposure was usually set at $30 \mathrm{~s}$ in the dark. Intensity profile analysis of photographs taken in the dark were carried out using a software for image analysis (Nikon NIS-Elements Basic Research). 

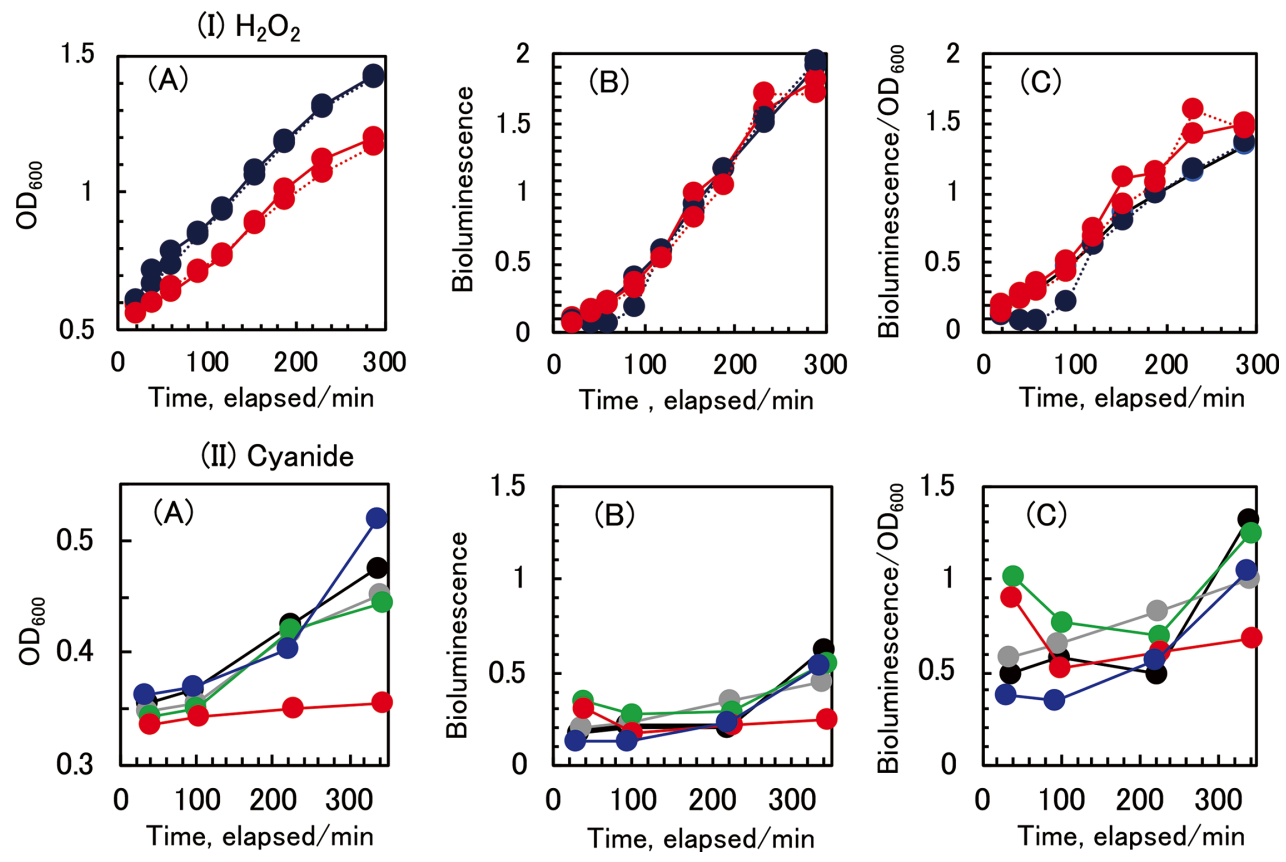

Fig. 1 Plots of $\mathrm{OD}_{600}(\mathrm{~A})$, relative bioluminescence intensity (B), and the ratio of relative bioluminescence intensity to $\mathrm{OD}_{600}(\mathrm{C})$ against time in the presence of $\mathrm{H}_{2} \mathrm{O}_{2}$ (I, upper panels) or cyanide (II, lower panels). Time/min, after the addition of $\mathrm{H}_{2} \mathrm{O}_{2}$, cyanide or IPTG. (I) ๑, IPTG (800 $\left.\mu \mathrm{M}\right)$; ○, $\mathrm{H}_{2} \mathrm{O}_{2}(20 \mu \mathrm{M})$. (II) $\bullet$, IPTG $(800 \mu \mathrm{M})$; cyanide $\left(\mathrm{mg} \mathrm{L}^{-1}\right) \bullet, 0.02 ; \bullet, 0.2 ; \bullet, 2$; and $\bullet, 20$. Concentrations are in the culture.

\section{Results and Discussion}

\section{Bioluminescence of E. coli-kat $G^{\prime}:: b m F P l u x C D A B F E$}

As shown in Fig. 1, the basic bioluminescence properties of the luminous E. coli construct was evaluated in the LB liquid medium in the presence of either $\mathrm{H}_{2} \mathrm{O}_{2}$ or IPTG, which is the lactose operon inducer fitting to the $\mathrm{T} 7$ promoter region.

The $20 \mu \mathrm{mol} \mathrm{L}^{-1}$ of $\mathrm{H}_{2} \mathrm{O}_{2}$ added in the culture was a higher level than that in the stationary E. coli cells, ${ }^{22,23}$ but it did not cause death of the cell. As shown, the addition of $\mathrm{H}_{2} \mathrm{O}_{2}$ induced bioluminescence within $20 \mathrm{~min}$ and the maximum light emission was obtained within $5 \mathrm{~h}$ after the addition. Taking into account that the concentration of IPTG was 40 times greater than that of $\mathrm{H}_{2} \mathrm{O}_{2}$, the fusion gene expression due to the presence of $\mathrm{H}_{2} \mathrm{O}_{2}$ appears to be effective. It is important to note that around $0.2 \mu \mathrm{mol} \mathrm{L}{ }^{-1}$ of $\mathrm{H}_{2} \mathrm{O}_{2}$ naturally occurs in E. coli cells for homeostatic regulation. ${ }^{23}$ Hence, such a stationary level of $\mathrm{H}_{2} \mathrm{O}_{2}$ is responsible for the background bioluminescence, as shown in Fig. 1 (I), (B) and (C).

The addition of cyanide also triggered bioluminescence, of which intensity depended on the cyanide concentration (Fig. 1). This was obviously reflected by the ratio of relative bioluminescence intensity to $\mathrm{OD}_{600}$ of the culture, as shown in Fig. 1 (II), (C). The induced bioluminescence once decreased and then increased again particularly at higher concentrations of cyanide. At the moment it is not easy to explain such a relationship. It may be necessary to consider that the effect of cyanide poising is complex and long-lasting even in E. coli cells like multicellular organisms. ${ }^{24}$ However, focusing on the fact that cyanide was responsible for the bioluminescence induction, the luminous $E$. coli construct was highly expected to be useful for cyanide sensing. As described below, it was found that the production of cyanide dependent bioluminescence could be regulated in the alginate microenvironment.
Bioluminescence in alginate sol for microplate assay of cyanide From the viewpoint of the practical application, the cyanide dependent bioluminescence of $E$. coli-kat $G^{\prime}:: b m F P l u x C D A B F E$ was characterized using a microplate in the presence of various concentrations of cyanide. In this characterization, the bioluminescence induction was carried out in the liquid culture in the presence of alginate and in its absence. Figure 2 shows the typical bioluminescence induced in the alginate containing LB medium.

As shown, bioluminescence was induced within $10 \mathrm{~min}$ after the addition of cyanide and the intensity reached around maximum at about $1 \mathrm{~h}$ or less. Importantly, the intensity profile shows that the light intensity increases with an increase in the cyanide concentration between about 0.01 and about $1 \mathrm{mg} \mathrm{L}^{-1}$. The bioluminescence faintly observed in the absence of neither IPTG nor the added cyanide is due to the steadily generated $\mathrm{H}_{2} \mathrm{O}_{2}$ as described above. Similar to the above, the light intensity at higher concentrations of cyanide, especially at $130 \mathrm{mg} \mathrm{L}^{-1}$, begins to increase an hour after the addition of cyanide.

Regarding the effect of the alginate viscosity, it was shown that the bioluminescence of E. coli-kat $G^{\prime}:$ :bmFPluxCDABFE cells increased with an increase in the viscosity of the alginate containing culture (Fig. S1, Supporting Information). As shown in Fig. S2 (Supporting Information), the cyanide induced bioluminescence is indeed made bright in the alginate containing LB medium as compared with that in the alginate free LB medium, while maintaining a positive correlation between the induced bioluminescence and the cyanide concentration irrespective of the presence of alginate. Taking into account the solubility of alginate, 1 to $1.5 \mathrm{w} / \mathrm{v} \%$ alginate in the culture seemed to be practical.

Bioluminescence of luminous cells immobilized in alginate gel By delaying the bioluminescence production, the microplate 

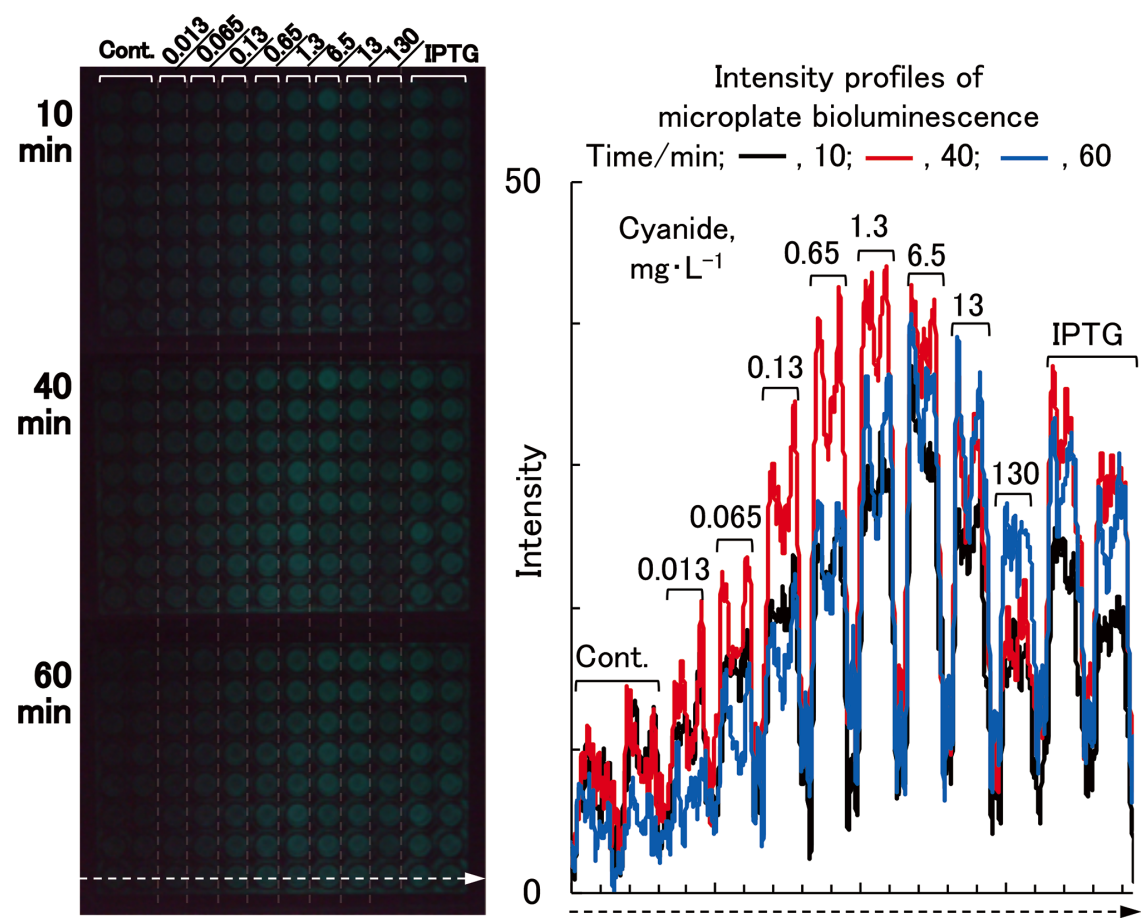

Fig. 2 Bioluminescence of a 96-well microplate containing E. coli-kat $G^{\prime}:$ :bmFPluxCDABFE cells, suspended in $1.3 \mathrm{w} / \mathrm{v} \%$ alginate containing LB medium, photographed at 10, 40 and $60 \mathrm{~min}$ after the addition of cyanide (left panel) and corresponding intensity profiles, obtained along the horizontal dotted arrow (right panel); $10 \mathrm{~min}$, black in profiles; $40 \mathrm{~min}$, red; and $60 \mathrm{~min}$, blue. Intensity, the average of each set of eight intensity profiles at 10,40 and $60 \mathrm{~min}$. Numerical values designated atop the photograph indicate cyanide concentrations $\left(\mathrm{mg} \mathrm{L}^{-1}\right)$ in each well. Exposure, $30 \mathrm{~s}$. IPTG, $200 \mu \mathrm{mol} \mathrm{L}{ }^{-1}$. Cont. (control), free of cyanide or IPTG.
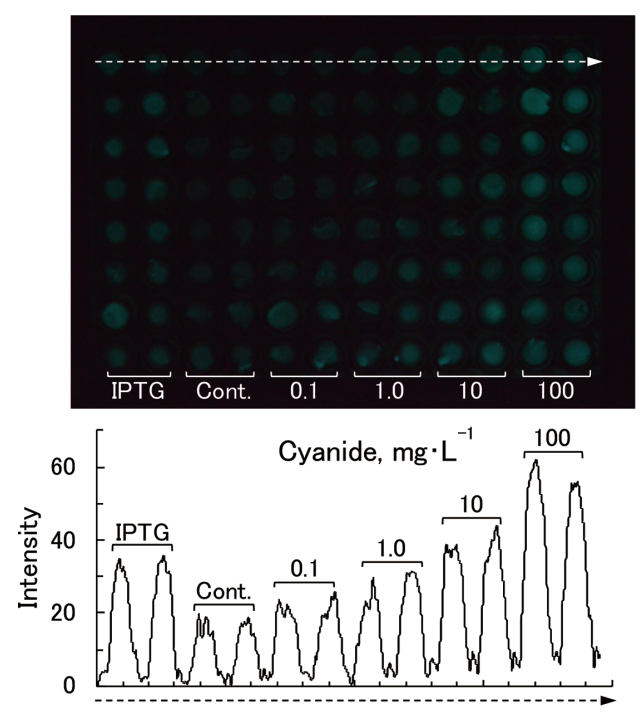
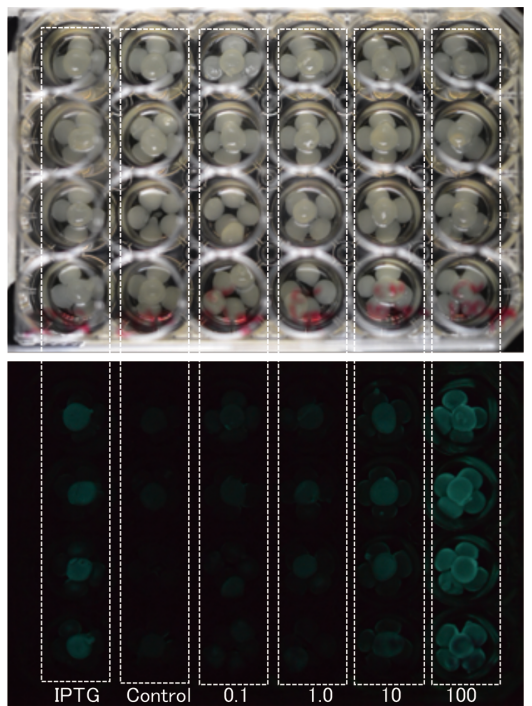

Fig. 3 Bioluminescence of a 96-well microplate with one E. coli-kat $G^{\prime}:$ bmFPluxCDABFE immobilized gel per well, photographed at about $12 \mathrm{~h}$ after the addition of cyanide, and corresponding intensity profiles obtained along the horizontal dotted arrow (left panels). In this run, 2YT medium was used. Intensity, the average of a set of eight intensity profiles. Alginate concentration for gelation, $1 \mathrm{w} / \mathrm{v} \%$. Right panels, photographs of 24-well microplates with five gels per well in the light (top) and in the dark (bottom). Numerical values indicate cyanide concentrations ( $\left.\mathrm{mg} \mathrm{L}^{-1}\right)$ in each well. Diameter of a gel, about $5 \mathrm{~mm}$. Exposure, $30 \mathrm{~s}$. IPTG, $8 \mathrm{mmol} \mathrm{L}^{-1}$. Cont. (control), free of cyanide or IPTG.

assay was expected to become more versatile in terms of the practical application. In relation to this, we have preliminarily found that immobilizing luminous E. coli cells in alginate gel delays the production of bioluminescence preferable for 
photographing. ${ }^{16}$ Based on this preliminary knowledge, E. coli$k a t G^{\prime}:$ :bmFPluxCDABFE cells were immobilized in spherical alginate gel for the microplate assay of cyanide. In a 96-well plate, each well was packed with one E. coli-kat $G^{\prime}:$ : bmFPluxCDABFE immobilized gel, and then $25 \mu \mathrm{L}$ of various concentrations of cyanide solution was added. A typical photograph taken in the dark is shown in Fig. 3 together with the corresponding intensity profiles.

Bioluminescence preferable for photographing was produced at about several hours or more after being exposed to cyanide. The intensity profile analysis showed that the bioluminescence intensity positively correlates with the concentration of cyanide in the range of 0.1 to $100 \mathrm{mg} \mathrm{L}^{-1}$. The delayed bioluminescence production could be explained by an idea that it takes a longer time for $\mathrm{CN}^{-}$ions to have an encounter with the immobilized cells in the alginate gel matrix due to the slow migration as compared with that in the alginate sol. ${ }^{25}$ In addition, it may be considered that the cell population in the logarithmic phase gradually increases in the alginate gel matrix to yield the strong bioluminescence more than several hours later. The photograph of the bioluminescence of a 24-well multiplate, packed with five luminous gels per well, implies that the stronger bioluminescence occurs on a gel surface exposed to the air. This also suggests that by improving the morphology of the alginate gel so as to provide wide contact with the air, more intense bioluminescence would be gained in association with the cyanide stimulation.

\section{Conclusions}

We conclude that E. coli-kat $G^{\prime}:: b m F P l u x C D A B F E$, cultured in alginate containing medium, is applicable for the bioluminescence microplate assay of cyanide. Regarding the mechanism for the bioluminescence production, cyanide, possibly transported via anion-selective pores in the cell membrane, ${ }^{26}$ binds to $\mathrm{Fe}^{3+}$ in cytochrome $c$ oxidase to interrupt the respiratory electron flow, followed by halting of $\mathrm{O}_{2}$ consumption. In such a case, oxygen molecules are reduced to superoxide anions by electrons leaked from the respiratory chain and subjected to disproportionation to give $\mathrm{H}_{2} \mathrm{O}_{2}$. Subsequently, an excess amount of $\mathrm{H}_{2} \mathrm{O}_{2}$ oxidizes the stress sensor protein OxyR so as to fit to the $k a t G^{\prime}$ region of the fusion gene (Fig. S3, Supporting Information), leading to the expression of bmFPlux gene cluster to produce bioluminescence. By making use either of alginate sol or of its gel in accordance with the purpose of use, visualizing cyanide in aqueous sample, ranging in concentration between about 0.01 and over $100 \mathrm{mg} \mathrm{L}^{-1}$, would become possible. Taking into account that the Japanese minimum effluent standard of total cyanide is $1 \mathrm{mg} \mathrm{L}^{-1}$ and that its environmental standard is less than $0.1 \mathrm{mg} \mathrm{L}^{-1}$, we deem that the proposed method meets these criteria. ${ }^{27,28}$

\section{Acknowledgements}

This work was supported by Japan Society for the Promotion of Science (JSPS) KAKENHI (Grant Numbers, 25440068 and 17K05899). The Grant from the 8th KRI's Challenging Exploratory Research is also acknowledged.

\section{Supporting Information}

This material is available free of charge on the Web at http:// www.jsac.or.jp/analsci/.

\section{References}

1. P. K. Onojah and E. M. Odin, Int. J. Innovation Sci. Math., 2015, 3, 2347.

2. F. B. Schmidt, S. K. Cho, C. E. Olsen, S. W. Yang, B. L. Møller, and K. Jørgensen, Plant Direct, 2018, 2, 1.

3. https://www.env.go.jp/hourei/05/000086.html.

4. B. Demple, Annu. Rev., Genet., 1991, 25, 315.

5. V. C. S. Italiani, J. F. da Silva Neto, V. S. Braz, and M. V. Marques, J. Bacteriol., 2011, 193, 1734.

6. L. A. Tartaglia, G. Storz, and B. N. Ames, J. Mol. Biol., 1989, 210, 709 .

7. T. K. van Dyk, W. R. Majarian, K. B. konstantinov, R. M. Young, P. S. Dhuriati, and R. A. Larossa, Appl. Environ. Microbiol., 1994, 60, 1414.

8. O. B.-Israel, H. B.-Israel, and S. Ulitzur, Appl. Environ. Microbiol., 1998, 64, 4346.

9. S. Belkin, D. R. Smulski, A. C. Vollmer, T. K. van Dyk, and R. A. Larossa, Appl. Environ. Microbiol., 1996, 62, 2252.

10. C. Wu and T. Kurinomaru, Anal. Sci., 2016, 35, 301.

11. E. A. Meighen, FASEB J., 1993, 7, 1016.

12. P. Dunlap, in "Bioluminescence: Fundamentals and Applications in Biotechnology", ed. G. Thouand and R. Marks, 2014, Vol. 1, Springer, 37.

13. J. Klumpp and M. J. Loessner, in "Bioluminescence: Fundamentals and Applications in Biotechnology", ed. G. Thouand and R. Marks, 2014, Vol. 1, Springer, 155.

14. J. W. Hastings, C. J. Potrikus, S. C. Gupta, M. Kurfürst, and J. C. Makemson, Adv. Microbiol. Physiol., 1985, 26, 235.

15. M. Wada, A. Kamiya, N. Uchiyama, S. Yoshizawa, K. K-Tsukamoto, K. Ikejima, R. Yu, C. Imada, H. Karatani, N. Mizuno, Y. Suzuki, M. Nishida, and K. Kogure, FEMS Microbiol. Lett., 2006, 260, 186.

16. H. Karatani, 17th Congress of the European Society for Photobiology, 2017, Abstracts, 74.

17. H. Karatani, T. Konaka, and C. Katsukawa, Photochem. Photobiol., 2000, 71, 230.

18. K. Y. Lee and D. J. Mooney, Prog. Polym. Sci., 2012, 37, 106.

19. S. J. Bidarra, C. C. Barrias, M. A. Barbosa, R. Soares, and P. L. Granja, Biomacromolecules, 2010, 11, 1956.

20. G. Simó, E. Fernández-Fernández, J. Vila-Crespo, V. Ruipérez, and J. M. Rodríguez-Nogales, Carbohydr. Polym., 2017, 170, 1.

21. H. Hassanvand and P. Hahemi, Anal. Sci., 2018, 34, 567.

22. I. Frindovich, Science, 1978, 201, 875.

23. B. G.-Flecha and B. Demple, J. Bacteriol., 1997, 179, 382.

24. E. B.-Reuss, T. P. Grady, and L. Reuss, J. Physiol., 1981, $314,343$.

25. M. Tokita, Jpn. J. Appl. Phys., 1995, 34, 2418.

26. R. Benz, R. P. Darveau, and R. E. W. Hancock, Eur. J. Biochem., 1984, 140, 319.

27. https://www.env.go.jp/water/impure/haisui.html.

28. https://www.env.go.jp/council/09water/y095-05/mat05.pdf. 